\title{
Representações de Loucura e Cuidado no Contexto das Residências Terapêuticas
}

\author{
Pedro Machado Ribeiro Neto ${ }^{1}$ \\ Luziane Zacché Avellar \\ Universidade Federal do Espírito Santo
}

\begin{abstract}
RESUMO - Este estudo foi realizado com objetivo de conhecer as representações sociais de loucuraede cuidado para habitantes de um bairroque recebe cinco residências terapêuticas, localizado em um município do sudeste brasileiro. Partimos de perspectiva etnográfica e realizamos entrevistas com pessoas que habitam ou trabalham nesse bairro. Da análise temática, sete categorias surgiram, sendo três no contexto das representações sociais de loucura e quatro sobre o cuidado, indicando duas vertentes principais: uma relacionada às ideias clássicas de loucura como doença e de seu cuidado como tratamento, ao passo que a segunda vertente indicou a existência de diálogo e troca de afeto entre participantes e moradores das residências terapêuticas localizadasno bairro em estudo, aspecto fundamental no contexto da desinstitucionalização.
\end{abstract}

Palavras-chave: representações sociais, loucura, cuidado, residências terapêuticas, etnografia

\section{Representations of Madness and Care in the Context of Therapeutic Residences}

\begin{abstract}
This study was realized with the objective to understand the social representations of madness and care for the inhabitants of a neighborhood that accommodates five therapeutic residences, located in a municipality in the southeast of Brazil. Interviews were conducted with inhabitants and workers of the neighborhood from an ethnographic perspective. Seven categories emerged from the thematic analysis, three in the context of social representations of madness and four related to the social representations of care. Two main tendencies were demonstrated: one about the classical ideas of madness as an illness and the care as treatment, the second indicated the existence of dialogue and exchange of affections between the participants of this study and the therapeutic residences dwellers, a fundamental aspect in the context of deinstitutionalization.
\end{abstract}

Keywords: social representations, madness, care, therapeutic residences, ethnography

Abordaremos as representações sociais de loucura, assim como de cuidado em relação à loucura, para habitantes de um bairro que recebe residências terapêuticas (RTs). De acordo com o Ministério da Saúde (MS), as RTs se constituem como moradia para ex-internos de hospitais psiquiátricos, que, com o período de internação prolongada, perderam os vínculos familiares e laços sociais. Dessa forma, as RTs possuem o objetivo de favorecer a reintegração de seus moradores à vida comunitária dos bairros onde passam a residir (Brasil, 2000, 2011b).

As RTs são parte constituinte da Rede de Atenção Psicossocial (RAPS), que possui como finalidades criar, ampliar e articular pontos de atenção à saúde, abarcando o contexto do cuidado em saúde mental, garantindo o respeito aos direitos humanos, à autonomia e à liberdade, entre outras diretrizes. A RAPS possui como um de seus componentes a estratégia de desinstitucionalização, e, nesse contexto, as RTs se configuram como importante ponto de atenção na desinstitucionalização da população egressa de longas internações psiquiátricas, pois, em tese, garante o direito de moradia, de ir e vir, entre outros (Brasil, 2011a, 2011b).

Luiz, Loli, Kawanichi e Boarini (2011), em levantamento bibliográfico sobre as RTs no Brasil, observaram a existência de experiências exitosas e também de dificuldades para

1 Endereço para correspondência: Programa de Pós-Graduação em Psicologia, Universidade Federal do Espírito Santo, Av, Fernando Ferrari, n. 514, Ed. Lídio de Souza, Campus Universitário de Goiabeiras, Vitória, ES, Brasil. CEP: 20.075-910.E-mail:mrn.pedro@ gmail.com a consolidação dos objetivos da desinstitucionalização. Apesar disso, os autores destacaram que as RTs possibilitam aos seus moradores "sua liberdade no que tange ao ir e vir, sua independência em relação às atividades diárias e a possibilidade de viver em comunidade" (p. 138). Nessa direção, Vidal, Bandeira e Gontijo (2008) realizaram pesquisa bibliográfica sobre desinstitucionalização, reforma psiquiátrica e tratamento comunitário, concluindo que os egressos de longas internações "podem viver em ambientes comunitários supervisionados, sendo beneficiados pela mudança do local de tratamento" (p. 77).

Observamos na literatura sobre as RTs no Brasil recentes estudos realizados com cuidadores (Silva \& Azevedo, 2011; Sprioli \& Costa, 2011; Argiles, Kantorski, Willrich, Antonacci, \& Coimbra, 2013), com profissionais que participaram do processo de implantação das RTs (Martins, Peres, Oliveira, Stipp, \& Almeida Filho, 2013), com usuários de CAPS, moradores e cuidadores de RTs (Furtado et al., 2013), pesquisa etnográfica no contexto das RTs (Moreira \& Castro-Silva, 2011; Ribeiro Neto, Avellar, \& Bonomo, 2016) e com os moradores das RTs (Matos \& Moreira, 2013). Esses estudos dão conta de que as RTs são dispositivos importantes para o cuidado extra-hospitalar da pessoa acometida por transtorno mental, porém, tratam de uma realidade constituída de aspectos favoráveis à reinserção, como a possibilidade de estabelecimento de laços entre moradores das RTs e a vizinhança, e de aspectos negativos, como o distanciamento e preconceito. 
Utilizamos a literatura sobre a experiência italiana como ponto de partida para abordar o processo de desinstitucionalização brasileiro, pois o movimento italiano se constituiu como um marco no cuidado em saúde mental no Ocidente. Um dos principais objetivos da desinstitucionalização italiana se referiu à garantia do direito à moradia para as pessoas que receberam alta dos hospitais psiquiátricos, aproveitando a vida comunitária como espaço de partilha de recursos bem como de trocas sociais e afetivas (Del Giudice, 1998; Rotelli, De Leonardis \& Mauri, 2001).

Nesse sentido, a reconstrução dos objetivos da atenção em saúde mental tornou-se questão principal nas últimas quatro décadas, contexto em que a assistência passou a utilizar os espaços da cidade como possibilidades de produção do cuidado: "O problema não é cura (a vida produtiva) mas a produção de vida, de sentido, de sociabilidade, a utilização das formas (dos espaços coletivos) de convivência dispersa" (Rotelli et al., 2001, p. 30).

No Brasil, a consolidação das RTs possibilitou o cuidado em saúde mental na comunidade, exercido por meio das relações com as pessoas que habitam, trabalham ou circulam pela vizinhança das RTs, situação imprescindível, principalmente, para a população egressa de longas internações psiquiátricas, pois "comunidade é um espaço intermediário que nos oferece os recursos simbólicos e materiais para a vivência da dialética entre o singular e o mundo social" (Jovchelovitch, 2008, p. 127).

No intuito de conferir consistência teórica ao nosso debate, utilizamos a Teoria das Representações Sociais (TRS) para analisar as representações de loucura e de cuidadoem relação à loucura no contexto da convivência com as RTs. As representações sociais podem ser entendidas como saberes, que, em geral, são compartilhados na esfera públicae funcionam como orientação de condutas individuais e grupais, relacionadas aos contextos em que são utilizadas (Jovchelovitch, 1998, 2000, 2008; Moscovici, 2012).

De acordo com Jovchelovitch (2000), as representações sociais são reproduzidas por meio da ação comunicativa decorrente dos processos de interação cotidiana e se constituem como mediação simbólica no contexto das trocas sociais: "É no encontro público de atores sociais, nas várias mediações da vida pública, nos espaços em que sujeitos sociais reúnem-se para falar e dar sentido ao cotidiano que as representações sociais são formadas" (p. 40). Apoiamonos na autora para debater a articulação existente entre representações sociais e espaço público, entendido como um lugar de encontro e de comunicação, que, ao mesmo tempo, permite a transformação das representações sociais: "A esfera pública - enquanto espaço da realidade intersubjetiva - é o terreno no qual elas são geradas, se cristalizam e se transformam" (p. 175).

O conhecimento sobre as representações sociais de loucura e de cuidado, principalmente para quem convive com as RTs, é importante para problematizar os processos de desinstitucionalização, pois as representações podem evidenciar o rumo das relações estabelecidas nos contextos que recebem as RTs, no entendimento de que "as representações sociais se tornam capazes de influenciar o comportamento do indivíduo participante de uma coletividade" (Moscovici, 2000/2012, p. 40).
Além disso, o conhecimento das representações sociais de loucura e cuidado proporciona informações necessárias para o debate sobre os processos de desinstitucionalização, possibilitando compreender os significados da convivência com moradores de RTsnos espaços públicos, como também, discutir as possibilidades dessa interação. Com base nesses referenciais teóricos, estruturamos este estudo com o objetivo de conhecer e analisar as representações sociais de loucura, assim como de cuidado em relação à loucura, na concepção de habitantes de um bairro onde se localizam RTs.

\section{Método}

No sentido de conhecer parte do cotidiano das relações estabelecidas no espaço público do bairro que recebe as RTs, fundamentamos nossa pesquisa de campo por meio de perspectiva etnográfica. Consideramos esse embasamento metodológico apropriado aos objetivos que estabelecemos, pois a etnografia possibilita contribuições importantes para a condução da pesquisa de campo: "Em qualquer situação, os etnógrafos se ocupam basicamente das vidas cotidianas rotineiras das pessoas que eles estudam" (Angrosino, 2009, p. 31).

$\mathrm{Na}$ pesquisa etnográfica, o pesquisador permanece em campo de estudo entre semanas e meses, realizando entrevistas, observações, conversas informais ou interações com os habitantes do local. Nesse percurso, a permanência em campo favorece a compreensão da cultura que se pretende apreender e, ao mesmo tempo, facilita a inserção do pesquisador no campo de estudo, tornando-se familiar e familiarizando-se com os habitantes do lugar (Angrosino, 2009; Minayo, 2004; Sato \& Souza, 2001).

Tendo como fundamento metodológico a perspectiva etnográfica, realizamos o estudo em um município do sudeste brasileiro, mais especificamente, em um bairro localizado aproximadamente a 10 quilômetros do centro da capital, onde se localizam cinco residências terapêuticas sob gestão estadual. Os dados foram coletados entre outubro de 2011 e fevereiro de 2012, contexto em que permanecíamos em campo, em cada momento de coleta, por um período de duas horas a quatro horas e meia. Durante a pesquisa, observamos a presença de uma pracinha na região central do bairro, espaço onde as pessoas se encontravam ou simplesmente passavam um tempo sentadas em um de seus bancos. A pracinha foi importante para o desenvolvimento da pesquisa de campo, pois nos possibilitou importantes momentos para observações e interações.

Em frente à pracinha, encontra-se uma padaria e, em seu andar superior, existe uma residência terapêutica. No interior do bairro podem ser observados espaços como quadra poliesportiva, bares, lanchonetes e igreja católica, além de três residências terapêuticas que ficam nas imediações da pracinha e outra que fica mais afastada dessa região central do bairro. O bairro, desde 2004, recebe as RTs e fica localizado próximo de um hospital psiquiátrico recentemente desativado, que se constituía como maior do estado, transformado em hospital clínico em 2012. Os moradores das RTs do bairro onde realizamos a coleta são provenientes desse hospital psiquiátrico. 
Os participantes são habitantes do bairro, sendo que alguns são também comerciantes, o que possibilitou a obtenção de relatos sobre a interação com os moradores das RTs nos comércios. Realizamos 24 entrevistas com roteiro semiestruturado, abordando as representações de loucura e de cuidado em relação à loucura na visão dos participantes. As entrevistas foram realizadas nos espaços públicos do bairro, como na praça, nas ruas e em alguns estabelecimentos comerciais, como bar, padaria e salão de cabeleireiro, nesses casos, com o consentimento dos comerciantes autorizando a pesquisa. Além disso, realizamos observações e conversas informais com outros habitantes e comerciantes da região, que não se configuraram propriamente como participantes, mas possibilitaram dados complementares às entrevistas, favorecendo a análise e interpretação dos resultados.

Optamos por não solicitar aos participantes sua assinatura no Termo de Consentimento Livre e Esclarecido, pois acreditamos que estes se sentiriam inibidos, de alguma forma, com a solicitação de assinatura, comprometendo a qualidade das informações concedidas nos relatos e a própria participação na pesquisa. Principalmente em uma pesquisa realizada no espaço público, a não coleta de assinatura retira o peso de determinados relatos considerados mais polêmicos. Assim, sem solicitar assinaturas, acreditamos que conferimos um tom mais leve e informal às entrevistas e adquirimos informações com mais sinceridade por parte dos participantes.

Porém, em conformidade com os aspectos éticos de pesquisa com seres humanos, os participantes foram esclarecidos sobre os objetivos da pesquisa, puderam abandoná-la caso optassem, permaneceram no anonimato, assim como foram informados de que as informações concedidas seriam publicadas em revistas ou congressos científicos. Todos os participantes, depois de estarem cientes destas ponderações, consentiram em sua participação.

Analisamos o material proveniente das entrevistas por meio da Análise de Conteúdo Temática, da forma como postula Minayo (2004). Segundo a autora, a expressão análise de conteúdo é frequentemente utilizada para representar o tratamento dos dados no âmbito da pesquisa qualitativa. Desse modo, parte-se da apreciação de um primeiro plano das informações coletadas para atingir um nível mais aprofundado. Essa modalidade de análise se divide em: pré-análise, exploração do material e tratamento dos dados, contexto em que ocorre, respectivamente, a leitura exaustiva de todo o material, depois se realizam recortes do texto em unidades de registro e finalmente, a organização e interpretação das categorias temáticas.

No que tange especificamente à análise dos dados dessa pesquisa, inicialmente, o material captado em áudio foi transcrito em sua totalidade, sendo posteriormente realizada a leitura exaustiva de todas as informações. A partir da continuidade dessa leitura, alguns temas foram se destacando, e, por meio da organização e interpretação destes recortes foi possível constituir as categorias temáticas que conferiram corpo aos resultados, como descritas no tópico a seguir.

\section{Resultados}

Apresentaremos os resultados a partir de duas seções principais de acordo com as questões que nortearam o roteiro das entrevistas: abordamos as representações de loucura, e, também, as representações de cuidado em relação à loucura, na visão de habitantes do bairro onde se localizam as cinco RTs. Na primeira seção, pesquisamos as representações dos participantes em relação à palavra loucura, solicitando que destacassem cinco termos associados à expressão. Três temáticas se sobressaíram nessa seção inicial e foram assim denominadas: dificuldade em definir loucura, doença mental e desconstrução da loucura. Já na segunda seção, indagamos aos participantes sobre as possibilidades de cuidado em relação à loucura, questionando-os especificamente sobre como cuidar de uma pessoa que enlouquece. Quatro temáticas foram recorrentes, sendo denominadas de acordo com as expressões surgidas nos relatos dos próprios participantes: tratamento, carinho, esses daqui e saber lidar.

A categorização temática realizada nos resultados foi elaborada no sentido de auxiliar em sua compreensão, e assim, as temáticas não se opõem, mas ao contrário, se inter-relacionam e se complementam. Em função disso, optamos por discutir os resultados no tópico posterior, à parte, englobando a totalidade das temáticas contidas nas duas seções dos resultados. Por fim, vale ressaltar que mantivemos as falas dos participantes apresentadas praticamente como elas foram relatadas, evitando realizar alterações gramaticais, no intuito de preservar a fidedignidade dos relatos.

\section{As Representações Sociais de Loucura}

Nesta primeira seção, debateremos as representações sociais de loucura na visão dos participantes. Observamos, no relato dos participantes, certa dificuldade em definir ou simplesmente discorrer sobre loucura, constituindo a primeira temática, que denominamos de dificuldade em definir loucura. No contexto dessa primeira temática, os participantes destacaram:"eu não posso falar que tem cinco palavras que se associa à loucura, não, porque hoje nós não descobrimos o que é a loucura". Essa dificuldade pode ser ilustrada pelas seguintes afirmações em relação à loucura: "dificil de explicar", "dificill, não sei","tem vários sentidos", "não sei como definir", "não tem definição", "eu não definiria".

Os participantes mencionaram aspectos familiares e de nascença para se reportar à loucura, como ilustraram as expressões: "uns já nasce com problema", "olha, pelo que a gente vê e ouve, a loucura pode existir de uma deficiencia de nascença, e ela pode desenvolver de acordo com a vida de cada um", "eu não sei se a loucura é a pessoa que faz ou se ela nasce, que até hoje eu não entendi ainda". Os participantes também se reportaram à loucura como uma experiência que foge a um estado comum de consciência ou de comportamento:"é um estado fora da consciência normal, da faculdade normal do indivíduo", como também demonstram: "A gente vive sob um padrão de comportamento, então qualquer coisa que foge ao padrão de comportamento, aceitável, assim, socialmente, a gente entende, ou a gente julga ou a gente rotula como loucura"; 
"É uma coisa que foge, assim, é uma coisa... além, vamos dizer, uma coisa oculta da mente. Então não sei como definir a loucura em algumas palavras, seria isso, uma coisa oculta, algo da mente...".

As expressões "um estado fora" "foge ao padrão" e "coisa que foge" delineiam essa dificuldade presente na definição de loucura. Com base nisso, e prosseguindo para a segunda temática, podemos afirmar que, para representar loucura, os participantes se reportaram à clássica ideia de doença mental, uma vez que o termo "doença", entre outros nesse sentido, foram recorrentes no relato dos participantes quando tentavam definir loucura: "a loucura é uma doença", "a loucura é uma enfermidade", "a esquizofrenia é terrivel".

Assim como "doença", observamos que a palavra "distúrbio" também foi utilizada pelos participantes para fazer referência à loucura, e, às vezes, foram utilizadas conjuntamente para representá-la: "A loucura é um distúrbio mental, uma doença que exige tratamento praticamente eterno, prá pessoa se manter, prá pessoa ter uma vida normal, tem que ter um tratamento diário"; "Loucura é distúrbio mental, a pessoa não pensa o que faz, não fica, não tem, não lembra de nada, é a perca da mente, né, a mente perde. Eu acho que o deles já é perca direta, irreversível. Talvez uns melhora, outros não".

No entanto, os participantes tentaram deixar claro que não entendem os moradores das RTs como loucos, uma vez que foi possível observar nos relatos uma forte tendência em desassociar a ideia de loucura em referência aos moradores das RTs do bairro, constituindo a terceira temática que denominamos desconstrução da loucura, podendo ser exemplificada pela seguinte expressão: "esse pessoal que tão aqui, eles não são completamente loucos". A tentativa de desassociar a ideia de loucura em relação aos moradores das RTs esteve amparada pela noção de distúrbio, como demonstram os seguintes relatos: "eu não vejo como loucura, eu vejo como um distúrbio que a pessoa tem", "parece que não são loucos, têm um disturbiozinho na cabeça, mas nada de...". A desconstrução da loucura observada no relato dos participantes também pode ser evidenciada pelas expressões: "eu nunca vi eles fazendo esse termo aqui, loucura, de dá um ataque forte, nunca vi", "acho que não existe gente doida, né", "acho que não existe louco".

\section{As Representações Sociais de Cuidado em Relação à Loucura}

Nesta seção apresentaremos as representações sociais de cuidado em relação à loucura, manifestas no momento em que os participantes relatavam sobre como cuidar de uma pessoa que enlouquece. Para facilitar a visualização e compreensão dos resultados, trabalhamos com quatro categorias temáticas, denominadas com base nas próprias expressões recorrentes no relato dos participantes, sendo assim intituladas: tratamento, carinho, esses daqui e saber lidar.

Grande parte dos relatos aludiu à primeira temática denominada de tratamento, podendo ser ilustrada, principalmente, pelas expressões "remédio", "médico", "tratamento" e "psiquiatra", recorrentes quando os participantes discorriam sobre o cuidado em relação à loucura. Um participante se reportou ao exemplo de seu irmão para discorrer sobre o cuidado nesse contexto: "Como cuidar.. quando eu vejo a parte do meu irmão, o que deixa ele mais orientado é o remédio que ele toma, né, o cuidado médico também influi muito nessas pessoas, mais ou menos normal, né".

De forma geral, no âmbito do cuidado associado a tratamento, os participantes afirmaram que: "o ideal é levar numa pessoa especializada, psiquiatra", "isso dai só médico", "eu acho que só internada", "tratamento médico com remédios, tratamento terapêutico e tratamento, assim, depois com esporte", "ai tem que ter tratamento psiquiátrico, um acompanhamento médico, os remédios na hora certa, prá ele poder sair dessa fase, né, de loucura" e, por fim, segundo os participantes, uma pessoa que enlouquece "tem que ser acompanhada por um psiquiatra, medicamento, certinho, $e$ tem que ter um responsável".

A segunda temática no contexto do cuidado em relação à loucura foi denominada de carinho, pois observamos a recorrência dos termos "carinho" e "amor" no relato dos participantes, como revelam as seguintes expressões: "um afeto de amor, carinho", "com carinho, com amor, com proteção", "ouvir, dar atenção, entendeu, eu acho que tem que ter... carinho", "além dos remédios, muito amor", "como o hospital, as associações fazem: carinho, amor e compreensão", "ama ao próximo como a si mesmo". Associamos a temática denominada de carinho com a que abordaremos a seguir, nomeada de esses daqui, pois, no momento em que os participantes discorreram sobre o cuidado relacionado à loucura, fizeram referência aos moradores das RTs, como expressam os relatos: "igual esses aqui, eu acredito que tem que ser assim mesmo, trazendo prá sociedade de novo", "dando amor e carinho, né, a gente dando atenção a eles... se vir conversar com a gente, a gente conversa", "quando eu passo, eu cumprimento, tento deixar eles à vontade".

Nesse segmento, os participantes afirmaram compartilhar os espaços sociais com os moradores das RTs sem maiores implicações: "eu não vou deixar de ir brincar com minha filha na pracinha por que têm doentes em tratamento ali do lado, de forma alguma". Além disso, os participantes relataram dispor de momentos de conversa com os moradores das RTs, ou seja, com esses daqui:"Essas daqui que tão aqui mesmo, que a gente se encontra com eles na rua, dá bom dia, boa tarde, sempre conversando com eles, já é uma forma de dizer assim 'pô, ninguém tá me excluindo', entendeu?"; "Têm pessoas que fica nas casas aí, que nem conversa direito, então você vai lá, ela conversa com você, por que você tem um jeito de tratar ela do jeito que ela gosta! Você não tem que tratar a pessoa de qualquer jeito não, você tem que tratar do jeito que ela acha melhor!".

Com base nos relatos que revelam a necessidade de carinho e nas análises que remetem, em parte, à experiência concreta de convivência com esses daqui, podemos observar o estabelecimento do diálogo nessa convivência dos participantes com os moradores das RTs, como o exemplo abaixo relatado por um participante que possui salão de cabeleireiro na região: "Um dos meninos chega aqui e começa a contar um negócio, eu dou atenção, eu ouço ele, 'ãnrrã, tá, 
você tá certo', tal, até onde eu acho que eu posso falar que tá certo, se eu achar que ele tá errado, "não, ce tá errado".

A última temática que abordaremos nesta seção se refere exatamente ao saber lidar dos participantes em relação aos moradores das RTs nas situações da convivência cotidiana. O "saber lidar" foi uma expressão recorrente no discurso dos participantes e se entrelaça às temáticas anteriores carinho e esses daqui, como foi possível observar nos relatos sobre o cuidado em relação à loucura: "ter carinho, atenção e saber levar ela, da forma que ela seja"; "você tem que tratar ela como se trata uma pessoa querida sua, com amor, tratar bem".

Entretanto, parte dos relatos evidenciou a dificuldade desse saber lidar: "aí fica complicado"; "porque, na verdade, a gente nunca sabe com o que a gente tá lidando". Assim, no contexto do cuidado em relação à loucura, "tem que ter muita vontade de tentar ajudar a pessoa, porque é meio sinistro lidar com uma pessoa doida, na mesma hora que ela tá bem, ela tá mal", e, nesse sentido "é fácil você falar 'vai lá e faz isso', mas é dificil lidar, saber lidar".

Ainda no contexto do saber lidar, os participantes afirmaram que as pessoas que enlouquecem "devem ser tratadas da mesma forma que a gente gostaria de ser tratado, e não ser tratada diferente como uma pessoa psiquiátrica". Desse modo,seria preciso "deixar ela fazer as mesmas coisas que a gente faz, que uma pessoa normal faz. Você trata do mesmo modo que você trata qualquer um, tá ligado?".

Para finalizar destacamos a resposta de uma participante quando discorria sobre o cuidado em relação à loucura: "Ter carinho, ter amor, ter paciência, não chamar aquela pessoa de louca, que é uma pessoa, não é louca, ela é dócil". Diante dessa suposta "docilidade" relacionada à loucura, a participante foi indagada se concordava com a existência de loucos agressivos e então afirmou: "Tem, tem louco agressivo sim!". Ao ser novamente questionada, dessa vez sobre como cuidar de um "louco agressivo", a participante respondeu, após refletir alguns segundos: "É a mesma coisa! Você ter paciência, ter carinho, saber lidar com ele. É você saber lidar!".

\section{Discussão}

O desconhecimento e a dificuldade inicialmente apontados pelos participantes no momento em que tentavam relatar suas definições sobre loucura podem ser entendidos, poisa loucura se constitui como fenômeno que se insere em um campo complexo de análise, e, nas palavras dos próprios participantes, representa "um estado fora", "uma coisa que foge", ou seja, remete a um fenômeno de difícil definição. Para dar conta desta dificuldade de definição, os participantes de nossa pesquisa tentaram fundamentar suas análises sobre loucura recorrendo a questões ligadas ao nascimento: "pelo que a gente vê e ouve, a loucura pode existir de uma deficiência de nascença". No entanto, ilustrando a ambiguidade da definição de loucura, a questão permaneceu em aberto, nas palavras de um dos participantes: "eu não sei se a loucura é a pessoa que faz ou se ela nasce".

Ribeiro Neto et al. (2016) realizaram pesquisa no contexto das RTs e observaram que os habitantes da vizinhança desses serviços, quando discorriam sobre a convivência com os moradores das RTs, reportavam-se a casos de familiares com transtorno mental, assim como às prováveis causas desse acometimento. Uma "macumba" realizada por um vizinho e um suposto abuso sexual, ambos na infância, teriam sido as causas dos "problemas de cabeça" dos parentes dos informantes.

No intuito de representar loucura, os participantes deste estudo se reportaram a saberes tradicionais, como as noções de "doença"e "distúrbio", para orientar suas respostas. Nessa linha, Jovchelovitch (2000) destaca que representações sociais ligadas a explicações biológicas são utilizadas para entender fenômenos sociais, como a loucura, e assim "continuam vivas no imaginário popular e incidem diretamente sobre os saberes ligados à esfera pública" (p. 21).

Para Duveen (2000/2012), as representações sociais são produto da comunicação cotidiana, ou seja, são constituídas "pelo que a gente vê e ouve", nas palavras de um participante. Da mesma forma, o autor pondera que as representações sociais, por meio da ação comunicativa, podem ligar ou, ao contrário, distanciar as pessoas umas das outras. Assim, a representação social da loucura como "distúrbio", e do cuidado como "tratamento", revelam resquícios de um discurso científico clássico, em que a internação e o isolamento são entendidos como principais formas de intervenção. Além disso, entendemos que as representações sociais se transformam em espaços simbólicos que conferem significado social para as ações práticas, e, assim, as representações sociais de loucura como doença, como também do cuidado em relação à loucura como tratamento médico, podem se constituir como obstáculos para a participação dos moradores das RTs na vida comunitária do bairro onde residem.

Entretanto, as representações sociais podem apresentar características contraditórias, aspecto que Moscovici (2000/2012) denominou de polifasia cognitiva. A partir desse conceito, "podemos compreender como é possível que, não apenas em sociedades diferentes, mas também dentro dos mesmos indivíduos, coexistam maneiras incompatíveis de pensamento e representações" (p. 329).

No contexto da polifasia cognitiva (Moscovici, 2000/2012), encontramos, inicialmente, as representações sociais de loucura e de cuidado associadas às ideias de doença mental e tratamento médico: "A loucura é um distúrbio mental, uma doença que exige tratamento praticamente eterno". Contudo, as representações sociais de loucura também indicaram uma direção oposta nos relatos, que chamamos dedesconstrução da loucura. Nesse sentido, notamos a desvinculação da ideia de loucura em relação aos moradores das RTs, como exemplificam as expressões "eles não são completamente loucos"e "eu nunca vi eles fazendo esse termo aqui, loucura, de dá um ataque forte".

Com base nessas informações, podemos afirmar que os participantes realizaram uma diferenciação dos moradores das RTs em relação à loucura. Isso pode ser entendido, já que, uma vez nas RTs, os moradores reconstroem "sua identidade, e tecem diariamente uma nova rede social. Além de deslocar a assistência do hospital para o território, permite também a criação de uma nova relação entre a loucura e a sociedade" (Fassheber \& Vidal, 2007, p. 196). Portanto, foi na 
experiência concreta de vida com os moradores das RTsque os participantes se fundamentaram para relatarque não os enxergam como loucos. Nessa esteira, podemos entender que "as representações sociais são inseparáveis da dinâmica do cotidiano, onde a mobilidade das interações do presente pode, potencialmente, desafiar tradições estabelecidas, abrindo novos sentidos para as tradições vindas do passado" (Jovchelovitch, 2000, p. 176). Contraditoriamente, os participantes utilizaram as representações ligadas ao distúrbio para realizar uma avaliação, de certo modo, positiva em relação aos moradores, pois a intenção era de retirar o aspecto negativo que acompanha a ideia de loucura, mesmo que por meio da concepção de distúrbio: "parece que não são loucos, têm um disturbiozinho na cabeça, mas nada de...".

Entendemos que as representações sociais possuem relação com os lugares em que operam, assim como com os processos de constituição identitária nos contextos em que são utilizadas: "Representações são construções sempre ligadas a um lugar a partir do qual sujeitos representam, estando, portanto, intimamente determinadas por identidades, interesses e lugares sociais" (Jovchelovitch, 1998, p. 77). Nessa linha, a avaliação dos moradores das RTs como "não loucos" pode ter uma função específica para os participantes, no sentido de evitar que se enxerguem seus novos vizinhos por meio de uma conotação negativa, implícita à concepção de loucura. Por isso, os participantes de nossa pesquisa, uma vez coabitando o mesmo espaço dos moradores das RTs, passaram a amenizar essa convivência a partir das representações de que esses daqui não são loucos, isto é, "têm um disturbiozinho, mas nada de...".

Observamos no relato dos participantes a ideia de que os moradores das RTs não são loucos, mas pessoas doentes, o que pode ser considerado um aspecto favorável à convivência. De fato, a literatura aponta a existência de estigma, porém, demonstra que as RTs são dispositivos que possibilitam aos seus moradores a reinserção social, a vida em liberdade e o exercício de práticas mais autônomas em relação às atividades do dia a dia (Vidal et a., 2008; Luiz et al., 2011; Moreira \& Castro-Silva, 2011; Argiles et al., 2013; Martins et al., 2013; Furtado et al., 2013). Desse modo, as representações sociais de loucura e cuidado "expressam os processos através dos quais uma comunidade produz o sistema de saberes que lhe confere uma identidade social, uma forma de enfrentar o cotidiano e uma forma de se relacionar com os objetos que o rodeiam" (Jovchelovitch, 1998, p. 80). Assim, entendemos que os moradores das RTs passaram a integrar aquele bairro também de forma simbólica, fazendo parte do lugar e compondo o cotidiano das relações estabelecidas no espaço público.

Em nosso estudo, observamos que as representações sociais do cuidado relacionado à loucura estiveram associadas à temática do carinho, o que, em certo sentido, pode revelar nuances de um "discurso politicamente correto", ou seja, de um discurso que seria, em tese, diferente na prática, utilizado para mostrar aos pesquisadores como o grupo de referência dos participantes é solidário, por exemplo. Ao mesmo tempo, a temática do carinho demonstra a possibilidade de uma troca afetiva na convivência entre participantes e moradores das RTs, aspecto fundamental no contexto da desinstitucionalização, possibilitado a partir do reconhecimento do outro como sujeito, como portador de valor e sentido, como afirma Del Giudice (1998).

Aparentemente, os participantes não se privaram de compartilhar os espaços públicos com moradores das RTs, a exemplo do pai que relatou brincar com sua filha na pracinha, mesmo com "doentes em tratamento ali do lado". Vale ressaltar que foi possível comprovar essa situação na ocasião da coleta de dados, na observação desse participante brincando com sua filha no parquinho da pracinha do bairro, momento em que os moradores das RTs se encontravam na praça, na companhia de um cuidador. $\mathrm{O}$ compartilhamento do espaço público entre os participantes e os moradores das RTs precisa ser destacado como aspecto positivo, pois revela que os habitantes da vizinhança das RTs pesquisadas estão, de certo modo, em sintonia com as políticas de saúde mental, não se privando de conviver junto dos moradores (Brasil, 2000, 2011b).

Os participantes demonstraram em seus relatos que estão "sempre conversando com eles", em referência aos moradores das RTs, e esse diálogo, associado às temáticas do carinho e esses daqui, compreendem um aspecto importante para os moradores das RTs de pertencimento a uma comunidade, pois: "É como membros de uma comunidade que nos tornamos nós mesmos, emergimos como atores sociais competentes e aprendemos a falar uma língua" (Jovchelovitch, 2008, p. 127).

Os relatos sobre a existência de diálogo entre os participantes de nosso estudo e os moradores das RTs do bairro precisam ser ressaltados, já que a conversa estabelecida no espaço público é um fator que favorece a convivência social: "A expressão dos nossos pensamentos sobre a realidade, sobre os outros e sobre nós mesmos é sempre feito através da fala, a fundadora da convivência" (Bibeau, 2013, p. 2809).

A convivência entre participantes e moradores das RTs foi possibilitada pela ação comunicativa no contexto dos espaços públicos do bairro em estudo, e, nessa esteira, auxilia nos processos de desinstitucionalização, na medida em que: "A única possibilidade de coincidência em perspectivas depende do diálogo, onde a ação e o discurso podem expressar tanto as similaridades como as diferenças entre os seres humanos" (Jovchelovitch, 2000, p. 50).

Apesar dessas informações que revelam a possibilidade de convivência entre participantes e moradores das RTs, os participantes ressaltaram a dificuldade de saber lidar com a loucura: "fica complicado", pois "a gente nunca sabe com o que a gente tá lidando", "na mesma hora que ela tá bem, ela tá mal" e, por isso, "é difícil saber lidar". Sobre essa dificuldade, Jovchelovitch (2008) argumenta: "O encontro entre a assim chamada sanidade mental e a loucura foi historicamente marcado por uma profunda ambivalência, em que predominaram as dificuldades daquela para estabelecer um diálogo com esta" (p. 245).

Mesmo com essa reconhecida dificuldade em relacionar com a loucura, destacamos que o "saber lidar", ressaltado com veemência pelos participantes de nosso estudo, esteve acompanhado por relatos que demonstram a existência de diálogo na esfera pública, evidenciando a existência de troca afetiva entre participantes e moradores das RTs. Trata-se de uma condição favorável para que as representações sociais de 
loucura e cuidado, associadas à doença e tratamento, sejam superadas por temáticas que se aproximam das quetambém encontramos neste estudo, como desconstrução da loucura, e posteriormente carinho, esses daqui e saber lidar.

As temáticas revelam que antigas representações se mantêm, mas, também, demonstram uma mudança nas tradicionais representações de loucura e cuidado, especialmente no que se refere às concepções de doença e tratamento. Retomando as contribuições de Fassheber e Vidal (2007), podemos afirmar que as RTs favorecem o estabelecimento de novas relações de troca afetiva entre a loucura e o espaço público, como também permitem a utilização de diversas representações no contexto do cuidado em saúde mental, além unicamente das representações de doença e tratamento.

Vale ressaltar que essa transformação em relação às representações de loucura e cuidado foi observada no contexto das representações sociais utilizadas por quem convive o cotidiano, compartilha os mesmos espaços e, principalmente, conversa com os moradores das RTs: "A fala é precisamente o produto de um processo contínuo de diálogo, conflito e confrontação entre o novo e o velho [...]. Neste sentido, as representações sociais são móveis, versáteis e estão continuamente mudando" (Jovchelovitch, 2000, p. 41).

A conversa estabelecida entre habitantes da vizinhança e os moradores das RTs favorece os processos de reintegração dos moradores à vida comunitária. Esse diálogo associado às representações sobre loucura e cuidado, como observado neste estudo indicam que os participantes, aparentemente, demonstraram saber lidar com os moradores das RTs e com a complexidade dessa convivência, o que constitui importante indicador principalmente nesse momento histórico da RAPS, em que as políticas de saúde mental direcionam o cuidado para as comunidades (Brasil, 2000, 2011a, 2011b).

De acordo com Del Giudice (1998), as transformações proporcionadas pela desinstitucionalização italiana, a partir do fechamento do hospital psiquiátrico e da criação de novos serviços de saúde mental inseridos nas comunidades, modificaram a própria cultura dos habitantes da cidade, favoravelmente à convivência com os egressos dos hospitais psiquiátricos. Essa informação pode ser utilizada para compreender o contexto atual no Brasil, tendo em vista as constatações deste estudo e a literatura consultada sobre as RTs, demonstrando que, apesar das dificuldades encontradas, as RTs têm funcionado como importante componente da RAPS na desinstitucionalização (Argiles et al., 2013; Brasil, 2011a; Martins et al., 2013; Furtado et al., 2013).

A maior parte das temáticas observadas neste estudo, e especialmente a temática do saber lidar, demonstra que os participantes encontraram possibilidades para se relacionar no dia a dia com os moradores das RTs, ilustradas pelos relatos sobre o estabelecimento da conversa no espaço público, o que pode ser considerado como aspecto imprescindível, pois, como mencionamos acima, tanto o diálogo como o afeto decorrente desse processo são ferramentas essenciais para possibilitar a convivência social com moradores das RTs. No entanto, esse aspecto favorável à desinstitucionalização que observamos nos relatos, ilustrado pela temática do saber lidar deve ser ponderado, pois surge imerso em uma rede de significados e concepções que abarcam diferentes vertentes e ilustram as contradições e a polissemia das representações sociais de loucura e cuidado.

\section{Considerações Finais}

Debatemos as representações sociais de loucura e de cuidado em relação à loucura a partir das concepções de habitantes de um bairro onde cinco RTs estão instaladas. Ao todo, sete temáticas surgiram a partir da análise dos resultados, sendo três na primeira seção, versando sobre as representações sociais de loucura, e quatro na segunda, abordando as representações sociais de cuidado em relação à loucura. De forma geral, as temáticas indicaram duas vertentes principais: uma relacionada às ideias clássicas de loucura como doença ou distúrbio e de seu cuidado vinculado a tratamento, ao passo que a segunda vertente indicou um aspecto mais favorável ao processo de desinstitucionalização, relacionado à dimensão afetiva. Assim, adesconstrução da loucura realizada pelos participantes e o cuidado em relação à loucura associadoàs temáticas carinho e saber lidar são elementos que destacamos e podem ser considerados fundamentais aos processos de desinstitucionalização.

Entretanto, nossos resultados precisam ser contextualizados, pois os participantes de nosso estudo habitam o bairro que cresceu nas imediações do hospital psiquiátrico do qual são provenientes os moradores das RTs. Por isso, há certa familiaridade dos participantes com a instituição psiquiátrica e também com seus antigos internos, denotando a dimensão afetiva que destacamos na discussão.

O método guiado por perspectiva etnográfica possibilitou observar o cotidiano e absorver parte das relações estabelecidas entre participantes e moradores das RTs do bairro em estudo. Citamos o exemplo da observação que fizemos em relação ao pai que brincava com sua filha na pracinha do local, praticamente ao lado dos moradores, sendo que, depois foi possível entrevistar esse pai, tendo esse relatado não evitar dividir os mesmos espaços públicos com moradores das RTs.

Além disso, conversamos com pessoas pelas ruas, praça, estabelecimentos comerciais e compartilhamos momentos de interação com habitantes e comerciantes, vivenciando o dia a dia, conversando informalmente, tomando café, enfim, nos inserindo no domínio das interações cotidianas para conhecer as representações sociais de loucura e cuidado na visão dos participantes. Nesse sentido: "as representações sociais estão radicadas nas reuniões públicas, nos cafés, nas ruas, nos meios de comunicação, nas instituições sociais e assim por diante" (Jovchelovitch, 2000, p. 40).

Foi possível observar moradores das RTs consumindo ou passando pelos comércios locais, e,nesse contexto, os comerciantes interagindo com estes, aparentemente, sem maiores implicações. Isso nos reaproxima da temática do saber lidar, ilustrando as possibilidades de convivência entre os participantes e moradores das RTs do bairro. Essa temática deve ser ressaltada, pois, evidencia que as RTs, ao menos em certo sentido, cumprem com seu objetivo de reintegração social. 
Mesmo com a existência de antigas representações sociais da loucura associadas à doença, como observadas em nossa pesquisa, foi por meio da convivência cotidiana com os moradores das RTs que os participantes os desvincularam da ideia de loucura, como também destacaram a importância do diálogo na esfera pública, ilustrando um aspecto positivo e imprescindível no contexto da desinstitucionalização, que precisa ser reforçado no cuidado em saúde mental: a dimensão afetiva.

As representações de loucura e cuidado se encontram inseridas em contradições, revelando que as relações estabelecidas e a própria convivência dos habitantes dos bairros com moradores das RTs são fenômenos complexos e que requerem respostas complexas, demandando a continuidade de estudos e intervenções nos contextos que recebem as RTs. Defendemos que esses estudos sejam construídos no sentido de fundamentar diretrizes políticas, embasadas, portanto, por meio do conhecimento da realidade cotidiana da convivência social com os moradores das RTs, e que as políticas suscitadas a partir das pesquisas possam garantir a participação plena dos moradores das RTs no cotidiano dos bairros onde passam a residir.

\section{Referências}

Angrosino, M. (2009). Etnografia e observação participante (J. Fonseca, Trad.). Porto Alegre: Artmed.

Argiles, C. T. L., Kantorski, L. P., Willrich, J. Q., Antonacci, M. H., \& Coimbra, V. C. (2013). Redes de sociabilidade: Construções a partir do serviço residencial terapêutico. Ciência \& Saúde Coletiva, 18(7), 2049-2058. doi: http://dx.doi.org/10.1590/ S1413-81232013000700020

Bibeau, G. (2013). O Humano entre a medida e a desmedida: O que são "evidências"?. Ciência \& Saúde Coletiva, 18(10), 2808-2812. doi: http://dx.doi.org/10.1590/S141381232013001000004

Brasil. (2000). Portaria 106 de 11 de fevereiro de 2000. Institui os Serviços Residenciais Terapêuticos no âmbito do SUS. Ministério da Saúde: Brasília, DF. Retrieved from <http:// portal.saude.gov.br/portal/saude/cidadao/visualizar_texto. cfm?idtxt=23119>.

Brasil. (2011a). Portaria 3.088 de 23 de dezembro de 2011. Institui a Rede de Atenção Psicossocial para pessoas com sofrimento ou transtorno mental e com necessidades decorrentes do uso de crack, álcool e outras drogas, no âmbito do Sistema Único de Saúde (SUS). Ministério da Saúde: Brasília, DF. Retrieved from <http://bvsms.saude.gov.br/bvs/saudelegis/gm/2011/ prt3088_23_12_2011_rep.html>.

Brasil. (2011b). Portaria 3.090 de 23 de dezembro de 2011. Altera a Portaria $\mathrm{n}^{\circ}$ 106/GM/MS, de 11 de fevereiro de 2000. Ministério da Saúde: Brasília, DF. Retrieved from <http://bvsms.saude. gov.br/bvs/saudelegis/gm/2011/prt3090_23_12_2011_rep. html>.

Del Giudice, G. (1998). Le strutture residenziali nel Dipartimento di Salute Mentale. Dipartimento di Salute Mentale Trieste, Trieste, Itália. Retrieved from <http://www.deistituzionalizzazionetrieste.it/letteratura/Letteratura/index.php>.
Duveen, G. (2012). O poder das ideias (P. Guareschi, Trad.). In S. Moscovici (Ed.), Representações sociais: Investigações em psicologia social (pp. 07-28). Petrópolis: Vozes. (Trabalho original publicado em 2000)

Fassheber, V. B., \& Vidal, C. E. L. (2007). Da tutela à autonomia: Narrativas e construções do cotidiano em uma residência terapêutica. Psicologia: Ciência e Profissão, 27(2), 194-207. doi: http://dx.doi.org/10.1590/S1414-98932007000200003

Furtado, J. P., Tugny, A., Nakamura, E., Braga-Campos, F. C., Guerra, A., Generoso, C., ... Baltazar, A. P. (2013). Modos de morar de pessoas com transtorno mental grave no Brasil: Uma avaliação interdisciplinar. Ciência \& Saúde Coletiva, 18(12), 3683-3693.doi: http://dx.doi.org/10.1590/S141381232013001200024

Jovchelovitch, S. (1998). Re(des)cobrindo o outro - Para um entendimento da alteridade na teoria das representações sociais. In A. Arruda (Ed.), Representando a alteridade (pp. 69-82). Petrópolis: Vozes.

Jovchelovitch, S. (2000). Representações sociais e esfera pública: A construção simbólica dos espaços públicos no Brasil. Petrópolis: Vozes.

Jovchelovitch, S. (2008). Os contextos do saber: Representações, comunidade e cultura. Petrópolis: Vozes.

Luiz, R. T., Loli, M. N., Kawanichi, N. K., \& Boarini, M. L. (2011). Estado da arte sobre o serviço residencial terapêutico no Brasil: Um panorama exploratório. Psicologia: Teoria e Prática, 13(1), 131-140.

Martins, G. da C. S., Peres, M. A. de A., Oliveira, A. M. B. de, Stipp, M. A. C., \& Almeida Filho, A. J. de. (2013). O estigma da doença mental e as residências terapêuticas no município de Volta Redonda-RJ. Texto \& Contexto - Enfermagem, 22(2), 327-334. doi: http://dx.doi.org/10.1590/S010407072013000200008

Matos, B. G., \& Moreira, L. H. D. (2013). Serviços residenciais terapêuticos: O olhar do usuário. Escola Anna Nery, 17(4), 668-676.doi: http://dx.doi.org/10.5935/1414-8145.20130010

Minayo, M. C. S. (2004). O desafio do conhecimento: Pesquisa qualitativa em saúde ( $8^{\mathrm{a}}$ ed.). São Paulo: Hucitec.

Moreira, M. I. B., \& Castro-Silva, C. R. (2011). Residências terapêuticas e comunidade: A construção de novas práticas antimanicomiais. Psicologia \& Sociedade, 23(3), 545-553. doi: http://dx.doi.org/10.1590/S0102-71822011000300012

Moscovici, S. (2012). Representações Sociais: Investigações em psicologia social (P. Guareschi, Trad.). Petrópolis: Vozes. (Trabalho original publicado em 2000)

Ribeiro Neto, P. M., Avellar, L. Z., \& Bonomo, M. (2016). Etnografia e desinstitucionalização da loucura: Um estudo no contexto das residências terapêuticas. Cadernos Brasileiros de Saúde Mental, 8(17), 57-77.

Rotelli, F., De Leonardis, O., \& Mauri, D. (2001). Desinstitucionalização, uma outra via. In F. Nicácio (Ed.), Desinstitucionalização (pp. 17-51). São Paulo: Hucitec.

Sato, L., \& Souza, M. P. R. (2001). Contribuindo para desvelar a complexidade do cotidiano através da pesquisa etnográfica em psicologia. Psicologia USP, 12(2). doi: http://dx.doi. org/10.1590/S0103-65642001000200003

Silva, D. S., \& Azevedo, D. M. (2011). As novas práticas em saúde mental e o trabalho no serviço residencial terapêutico. Escola Anna Nery, 15(3), 603-609. doi: http://dx.doi.org/10.1590/ S1414-81452011000300023 
Sprioli, N., \& Costa, M. C. C. (2011). Cuidar em novo tempo: $\mathrm{O}$ trabalho de cuidadores com pacientes psiquiátricos em moradias. Revista Latino-Americana de Enfermagem, 19(5), 1155-1162. doi: http://dx.doi.org/10.1590/S010411692011000500013
Vidal, C. E. L., Bandeira, M., \& Gontijo, E. D. (2008). Reforma psiquiátrica e serviços residenciais terapêuticos. Jornal Brasileiro de Psiquiatria, 57(1), 70-79.doi: http://dx.doi. org/10.1590/S0047-20852008000100013

Recebido em 18.08 .2014

Primeira decisão editorial em 01.09.2015

Versão final em 16.02.2017

Aceito em 20.06.2017 